\title{
'EU' DEVO ASSUMIR A RESPONSABILIDADE DO INCONSCIENTE
}

Christian Hoffmann

Psicanalista, professor titular de psicopatologia na Université de Poitiers

Tradução: Simone Perelson

RESUMO: Desenvolve-se a idéia freudiana de que a responsabilidade do sujeito ( 0 analisando) refere-se à coragem de deixar falar o inconsciente; a responsabilidade do psicanalista depende da resposta que ele dá à questão quem fala?.

Palavras-chave: Responsabilidade, inconsciente, analisando, psicanalista.

ABSTRACT: 'I' should take on the unconscious responsibility. It develops the Freudian idea that the subject's responsibility (the analyzed) It refers to the courage of letting the unconscious talk; the psychoanalyst's responsibility depends on the answer he gives to the question who speaks?.

Keywords: Responsibility, unconscious, the analyzed, psychoanalyst.

"O médico deixará ao jurista construir para fins sociais uma responsabilidade que é artificialmente limitada ao ego metapsi cológico."

(Freud, 1925/ 1976, p.167)

0

domínio da responsabilidade se divide classicamente entre 'responsabilidade civil', ' responsabilidade jurídica' e'responsabilidade moral'. Iremos nos interessar pelo sentido psicológico e moral da palavra, o qual é bem anterior ao sentido social, civil ou penal. Sua definição psicológica une, num laço de solidariedade, o sujeito a seu ato, o que o coloca na situação de ter de responder por este. Podemos acrescentar a este laço as suas conseqüências, que Ihe são igualmente atribuíveis. A psicanálise retoma este vocabulário, invocando a responsabilidade do sujeito do inconsciente e a responsabilidade do psicanalista. Iremos seguir Freud através de sua obra; de- 
pois Lacan, para examinar o que da psicanálise permite fundar uma responsabilidade do sujeito, privando-se de uma vontade unificada, que éo meio e o fim de nossas organizações sociais, sobretudo no mundo de hoje, onde o sujeito é convidado a tornar-se mestre de si mesmo.

Desenvolvemos, há alguns anos (GORI e HOFFMANN, 1999) - apoiandonos em W innicott e na teoria do sujeito em Lacan - a idéia de que na adolescência há um sujeito capaz de se deixar interpelar pelo Outro e de responder pelos seus atos. 0 psicanal ista se dirige desta forma ao sujeito do inconsciente na transferência com um adolescente. A conseqüência sobre a transferência é radical. É que 0 adolescente reclama com todo o seu corpo, pedindo justamente que the falemos como a um adulto-responsável.

\section{A RESPONSABILIDADE MORAL DO CONTEÚDO DOS SONHOS}

Encontramos a referência primordial de Freud à responsabilidade no segundo capítulo de "Algumas notas adicionais sobre a interpretação dos sonhos como um todo" (FREUD, 1925/ 1976). O capítulo tem por título: "Responsabilidade moral pelo conteúdo dos sonhos". Efetivamente, a famosa natureza imoral dos sonhos serve sempre como argumento para a rejeição do valor do sonho e de sua interpretação: "se os sonhos são o produto inexpressivo de uma atividade mental desordenada, não pode então haver fundamento para assumir responsabilidade (Verantwortlichkeit) por seu conteúdo aparente" (idem, p.163).

A questão da responsabilidade do conteúdo manifesto do sonho foi resolvida desde A interpretação dos sonhos:

"Se ol harmos para os desejos inconscientes reduzidos à sua mais fundamental e verdadeira forma, teremos de concluir, fora de dúvida, que a realidadepsíquica é uma forma especial de existência que não deve ser confundida com a realidadematerial. Desse modo, não parece haver justificativa para a relutância das pessoas em aceitar a responsabilidade pela imoralidade de seus sonhos." (FREUD, 1900/ 1976, p. 658-59)

Freud retoma aqui sua argumentação do fim de A Interpretação dos sonhos, assinalando novamente com precisão que o conteúdo manifesto do sonho é um engano e que não há razões para se chocar mais nem com as ausências de moral nem com os atentados à lógica.

O que chamamos de 'conteúdo' do sonho são os pensamentos pré-conscientes e 0 desejo recalcado revelado pela interpretação. Entretanto, resta saber por que a censura, habitualmente tão severa na formação do sonho, não barra 0 acesso ao conteúdo manifesto de seus pensamentos imorais. A resposta de Freud é de três ordens: estes pensamentos não significam nenhuma verdade inconsciente; a angústia vem no lugar da censura nos casos em que esses pensamentos 
significam uma moção imoral inconsciente; o gozo do sonhador pode significar a ausência de angústia ou a indulgência do sujeito.

Freud nos convida a constatar, corajosamente, que a maioria de nossos sonhos, uma vez interpretados, revelam a realização de desejos imorais: egoístas, sádicos, perversos, incestuosos.

Sem mais desvios, Freud abraça a questão da responsabilidade indicando sua falta de atualidade, a partir da descoberta dos pensamentos latentes do sonho e do recalcamento. É evidente, diz ele, que devemos nos responsabilizar pelo conteúdo do sonho: "a menos que o conteúdo do sonho (corretamente entendido) seja inspirado por espíritos estranhos, ele faz parte de seu próprio ser" (1925/ 1976, p.165). Freud é firme e convincente em sua firmeza: “Eu devo assumir a responsabilidade" do que é desconhecido, inconsciente em mim (em meu "Eu") ou então não estou mais no terreno da psicanálise.

A metapsicologia freudiana nos ensinou a não separar o 'Eu' do 'Isso' pulsional, na medida em que ele não é senão a parte periférica que sofre suas influências e acaba por Ihe obedecer. Essa separação seria, para Freud, um caminho sem volta. A clínica da neurose obsessiva mostra bem a culpabilidade de um 'Eu' em face de todas as espécies de pensamento que ele não pode reconhecer como the pertencendo. 0 ser normal não se priva desta organização psíquica. Impõe-se a constatação freudiana de uma consciência moral que é uma formação reativa contra o mal percebido no 'isso'. A força da repressão da pulsão é proporcional à severidade da consciência moral.

Deixemos a última pal avra a Freud, que sugere àquele que quer ser 'melhor' que a sua natureza humana ver se consegue produzir algo que não hipocrisia ou inibição.

\section{A IRRESPONSABILIDADE DA MASSA}

Quando se trata da massa, diz Le Bon, o heterogêneo desaparece no homogêneo. A singularidade cede diante do idêntico. $O$ que um sujeito pode ganhar ao se despir assim de sua singularidade? A resposta de Le Bon satisfaz Freud (FREUD, 1921/ 1976, p.98), pois a massa Ihe dá um sentimento de poder capaz de suspender o recalcamento das pulsões às quais ele não poderia ceder de outro modo. É aqui que Freud introduz a responsabilidade do sujeito, ${ }^{1}$ na medida que este sentimento fixa o sujeito. Por outro lado, 0 anonimato da massa, a causa de sua irresponsabilidade, permite ao sujeito desembaraçar-se de sua própria responsabilidade. 0 que leva ao desaparecimento da consciência moral ou do sentimento

${ }^{1}$ Sobre a questão de como fundar a possibilidade de uma responsabilidade singular, cf. S. Thibierge, 2003. 
de responsabilidade. Espanto algum para Freud, que já havia reconhecido que 0 cerne desta consciência é constituído de angústia social.

\section{UMA VONTADE UNIFICADA?}

"Responsável ou irresponsável?", estes veredictos da alternativa jurídica, diz Freud (1926/ 1976, p.252), não se adaptam aos neuróticos. Esta questão da responsabilidade surge aqui a propósito da vontade do sujeito de não querer curar-se de sua doença: "Este doente (...) é ele quem gostaria de não se curar." A resposta de Freud se fundamenta na unidade perdida do Eu: "O doente quer certamente se curar, mas ao mesmo tempo ele não quer." Ele não pode "elaborar uma vontade unificada", senão ele não seria neurótico. 0 Eu ( M oi) do neurótico é o lugar do retorno do recalcamento pulsional contra o qual ele não pode lutar, o que faz com que esse eu seja o lugar do desconhecimento: "ele não sabe habitualmente nada" sobre o pulsional que o ocupa.

Somos forçados a observar, como faz Freud, que todas as nossas instituições sociais são talhadas para pessoas com um eu unificado, normal, que se pode etiquetar de bom ou mal, que ou bem assume a sua função ou bem é excluído desta em função de uma influência excessivamente poderosa. Esta constatação é hoje extremamente atual num mundo em que cada um é solicitado a tornar-se mestre de si mesmo.

Freud prossegue o diálogo retomando o exemplo da reação terapêutica negativa que se opõe à cura, preferindo os benefícios secundários da doença ( o gozo da doença). Cito-0: "formou-se no eu do doente uma moção de vontade, que quer manter a doença (...)". Este propósito de Freud contribui muito para que nos interroguemos sobre o que funda a responsabilidade do sujeito freudiano em relação à sua definição jurídica.

Por hora, junto com Freud, admitimos que a psicanálise permitiu reconhecer que "é muito raro a complexidade de um caráter humano, impelida por um lado por outras forças dinâmicas, submeter-se a uma escol ha entre al ternativas simples, como levaria a crer nossa doutrina moral antiquada" (1900/ 1976, p.659).

\section{A PARTICIPAÇÃO DO SUJ EITO EM SUA DESORDEM NEURÓTICA}

"Olha para tua participação na desordem da qual te queixas." Eis a resposta que Freud dá à reivindicação da 'bela alma' na pessoa de Dora, que havia Ihe lançado o seguinte desafio: "Estes são os fatos; eles resultam da real idade (que a oferece sem defesas à sedução de M.K., seu pai tendo fechado os olhos para o seu rebaixamento a um objeto de troca) e não de mim mesma. 0 que você quer mudar nisso?" Eis a resposta do analista, a qual permitiu uma reversão dialética no tratamento de Dora, reversão esta que Ihe permitirá perceber sua participação sub- 
jetiva na corte da qual era o objeto e na ficção da quadrilha que lhe permitira sustentar, até então, o seu desejo (LACAN, 1966).

Nesta parte de gozo encontra-se a participação do sujeito, e ela implica a questão da escolha (HADDAD, 1995), assim como Freud fala da escolha da neurose e até mesmo da recusa da cura.

Podemos agora dar um salto com Lacan e reconhecer que "por nossa posição de sujeito, somos sempre responsáveis" (LACAN, 1966, p. 858).

\section{O QUE DEVO FAZER?}

A ética da psicanálise se articula a um Sollen, um dever que em nada deixa a desejar a Kant, o que o adágio freudiano diz muito justamente: "dali onde isso estava, Eu devo advir". No fundo, diz M. Safouan em sua análise do seminário de Lacan sobre a ética:

“( ...) a fórmula de Lacan: 'o desejo é a sua interpretação' é a mesma que aquela que descreve o processo de análise como uma travessia do fantasma. Ora, este desejo de jogar fora a máscara (como indica, por exemplo, o lapso) aponta para um dever particular, aquele que se exprime no adágio: 'dali onde isso estava, Eu devo advir'." (SAFOUAN, 2001, p. 140)

Nisto a ética da psicanálise é uma ética do desejo de "elucidar o inconsciente do qual vocêé o sujeito" (LACAN, 2001, p. 199). Resta acrescentar: "mas todos sabem que eu não encorajo ninguém, ninguém cujo desejo não esteja decidido". Em outros termos: "não pergunta'o que fazer' senão aquele cujo desejo se apaga".

\section{A RESPONSABILIDADE DO PSICANALISTA}

Como acabamos de ver, a responsabilidade do sujeito (o analisando) está relacionada à coragem de deixar falar o inconsciente, o que Freud reconhecia no poeta, não sem chamar a atenção sobre o limite próprio à estética, a saber, a produção de gozo.

Com Dora, já respondemos à questão da responsabilidade do analista, na medida que "é ele, em suma, quem, como auditor ou como ouvinte, funda 0 sujeito que se dirige a ele" (SAFOUAN, 1983, p.47). É do analista que depende a resposta à questão quem fala? Pela escolha que faz da interpretação do sentido do discurso que lhe é dirigido, ou do que aprende da condição do sujeito falante. Assim, um analista de língua estrangei ra atribuirá a sua impossi bilidade de dizer à sua impotência de desempenho na língua estrangeira, isto até a sua descoberta da impossibilidade de dizer o 'maternal' em sua língua de origem. Este impossível é a condição estrutural do sujeito falante. 


\section{REFERÊNCIAS}

FREUD, S. (1976) Edição standard das obras psicológicas completas de Sigmund Freud. Rio de Janeiro: Imago.

(1900) "A interpretação dos sonhos", v.lV eV.

(1921) "Psicologia de grupo e a análise do ego", v. XVIII, p.87-179.

(1925) "Algumas notas adicionais sobre a interpretação de sonhos como um todo", v. XIX, p. 155-173.

(1926) “A questão da análise leiga”, v. XX, p.205-293.

GORI, R. e HOFFMANN, C. (1999) La science au risque dela psychanalyse. Paris: Erès.

HADDAD, G. (1995) "La responsabilité du sujet et le discours freudien", LeTrimestre Psychanalytique n.1, ALI.

HOFFM ANN, C. (2001) Introduction à Freud. Le refoulement de la véité Hachette Pluriel.

LACAN, J. (1966) "La science et la vérité" e "Intervention sur le transfert", in Écrits, Paris: Seuil.

(1974) Tééision, Paris: Seuil.

SAFOUAN, M. (1983) Jacques Lacan et la question de la formation des analystes, Paris: Seuil. (2001) Lacaniana, Paris: Fayard.

THIBIERGE, S. (2003) “M assenpsychologieet logique du sujet, ou Pourquoi I'on ne se sauve pas seul", La Célibataire n.7, EDK.

Christian Hoffmann

hoffmann.ch@wanadoo.fr 